\title{
Ultrastructure of an Extremely Thermophilic Acidophilic Micro-organism
}

\author{
By G. MILLONIG* \\ CNR Laboratorio di Embriologia Molecolare, Arco Felice, Naples, Italy \\ M. DE ROSA AND A. GAMBACORTA \\ CNR Laboratorio per la Chimica e Fisica di Molecole di Interesse Biologico, Arco Felice, \\ Naples, Italy \\ AND J. D. BU'LOCK \\ Microbial Chemistry Laboratory, Department of Chemistry, \\ The University, Manchester M139PL
}

(Received 4 July 1974; revised 26 August 1974)

\begin{abstract}
SUMMARY
A thermoacidophilic micro-organism, isolated from volcanic hot springs near Naples, was cultivated in vitro, and examined by electron microscopy in sections and after negative staining. The cells were almost spherical, with a diameter of about 0.7 to $\mathrm{I} \cdot 0 \mu \mathrm{m}$. Their morphology was very primitive: the protoplasm was composed only of ground cytoplasm, ribosomes, and randomly distributed DNA strands. They were surrounded by a plasma membrane and by an extracellular coat about $20 \mathrm{~nm}$ thick which displayed a regular hexagonal pattern. Cell replication occurred by binary fission with median constriction during which a bipolar localization of nuclear material was observable. The morphology is compared with that of other known micro-organisms living in similar habitats.
\end{abstract}

\section{INTRODUCTION}

Six strains of acidophilic thermophilic micro-organisms, designated мт 2, 3, 4, 6, 8 and 9, were isolated from volcanic hot springs at Agnano. The MT3 and MT4 isolates were examined at the fine-structure level.

\section{METHODS}

The morphology was investigated by electron microscopy, applying mainly two conventional techniques of fixation, as well as negative staining. For comparison, samples of Sulfolobus acidocaldarius, kindly supplied by Dr J. A. Mosser, were also examined.

Cells of мT3 and MT4 cultures during the lag, logarithmic and stationary phases of growth (de Rosa, Gambacorta \& Bu'lock, 1975) were processed for electron microscopy. Attempts to fix the micro-organisms directly in the culture medium by adding glutaraldehyde, potassium permanganate, or osmium tetroxide resulted in severe damage to the fine structure. Evidently the acid medium, $\mathrm{pH} 3.5$, produced a coarse precipitation of the cytoplasm at the moment of fixation. However, the cells were better preserved when separated by low-speed centrifugation from the culture medium and fixed in a buffered fixative at $\mathrm{pH} 7 \cdot 2$, or when the medium was rapidly brought to $\mathrm{pH} 6.7$ with $\mathrm{NaOH}$ and then mixed with fixative. Fixation was also improved by using $\mathrm{I} \cdot 5 \%(\mathrm{w} / \mathrm{v})$ glutaraldehyde concentrations, instead of the commonly used 2 to $6 \%$.

* Present address: Ospedale Generale Provinciale 'S. Andrea', Laboratorio di Anatomia Patologica, Vercelli, Italy. 
Cultures of the MT 3 and MT4 strains were centrifuged at not more than $1500 \mathrm{~g}$ for $\mathrm{I} 5$ to 30 min and resuspended in $0 . \mathrm{I} \mathrm{M}$-phosphate buffered $\mathrm{I} .5 \%(\mathrm{w} / \mathrm{v})$ osmium tetroxide at $\mathrm{pH} 6.8$ or in $1.5 \%(\mathrm{w} / \mathrm{v})$ glutaraldehyde at $\mathrm{pH} 7 \cdot 2$, followed by osmium. With $0.2 \% \mathrm{NaCl}$ in the fixatives and rinsing solutions, swelling of the cells was reduced. Fixation time of both fixatives was I h. After acetone dehydration the samples were embedded in low-viscosity resin (Spurr, I969), sectioned with a diamond knife (GeFeRi, Italy) and the sections stained with uranyl acetate and lead citrate. For negative staining osmium tetroxide ( $1.5 \%$ ) was added to a cell suspension, which was then centrifuged at $1000 \mathrm{~g}$, and the sediment mixed first I : I (w/v) with distilled water and subsequently with $2 \%$ aqueous phosphotungstic acid at $\mathrm{pH} 6 \cdot 0$, and deposited on carbon-coated celloidine films. A Hitachi HS- 8 microscope was used at $50 \mathrm{kV}$ acceleration voltage.

\section{RESULTS}

Most observations refer to the MT3 strain. Those made on the MT4 suggest that the morphology of both strains is identical.

Pilot experiments confirmed the plasticity of these cells. When centrifuged, before or even after fixation, at centrifugal forces as low as $3000 \mathrm{~g}$ to form a compact pellet, the cells in section appeared compressed against each other and consequently polygonal, irregular or multilobar in outline (de Rosa, Gambacorta, Millonig \& Bu'Lock, 1974). The cells retained their configuration throughout further processing (e.g. glutaraldehyde fixation) and did not return to their original shape (Fig. I). The centrifugal force was therefore reduced to a minimum and the cells thoroughly resuspended at each step of processing so as to minimize these effects. With these precautions the cells appeared almost spherical, agreeing with their microscopic appearance when viewed under phase contrast. The slight irregularities of the contours observed in the sections may be real or may be artefacts of fixation or dehydration.

When the micro-organisms were fixed in glutaraldehyde their diameter was about $0.75 \mu \mathrm{m}$ and the cytoplasm appeared rather dense and uniform (Fig. 2). A large number of dark granules, presumably ribosomes, could be discerned. In some cultures the cells contained one or more large $(0.2 \mu \mathrm{m})$ clusters of strongly osmiophilic granules each about $10 \mathrm{~nm}$ in diameter, which were occasionally located in a clear phase (Fig. 4). After glutaraldehyde fixation the fine DNA strands could not be seen since the ground cytoplasm was too dense and dark.

Osmium-fixed cells appeared slightly swollen and less dense, due to extraction of organic material (Figs. 3 and 5). The granules considered to be ribosomes appeared less dense but more distinct. A loose irregular network of fibrils, not detectable in the glutaraldehyde-fixed samples, was now clearly recognized throughout the cytoplasm. The fibrils varied considerably in thickness, from $20 \mathrm{~nm}$ to less than $3 \mathrm{~nm}$, and were often branched. They resembled the condensed DNA strands in the nucleoid of bacteria, in mycoplasms, and in mitochondria. However, distinct nuclear areas, similar to a nucleoid, could be identified only during cell division (see below).

On the surface of the organism a plasma membrane and an extracellular coat could be distinguished (Fig. 6). The pattern of these structures appeared identical after osmium and glutaraldehyde fixation. The plasma membrane appeared as a typical trilaminar unit membrane about $8 \mathrm{~nm}$ thick. Within the extracellular coat two distinct components could be distinguished, an electron-transparent layer about $10 \mathrm{~nm}$ thick and an electron-dense exterior layer about $8 \mathrm{~nm}$ thick. In sections perpendicular to the cell surface the two 'layers' were resolved as a sequence of arches. It appears as if unstained 'globular particles' were covered by a dense coat material. Since, however, the 'globules' could not be demonstrated 

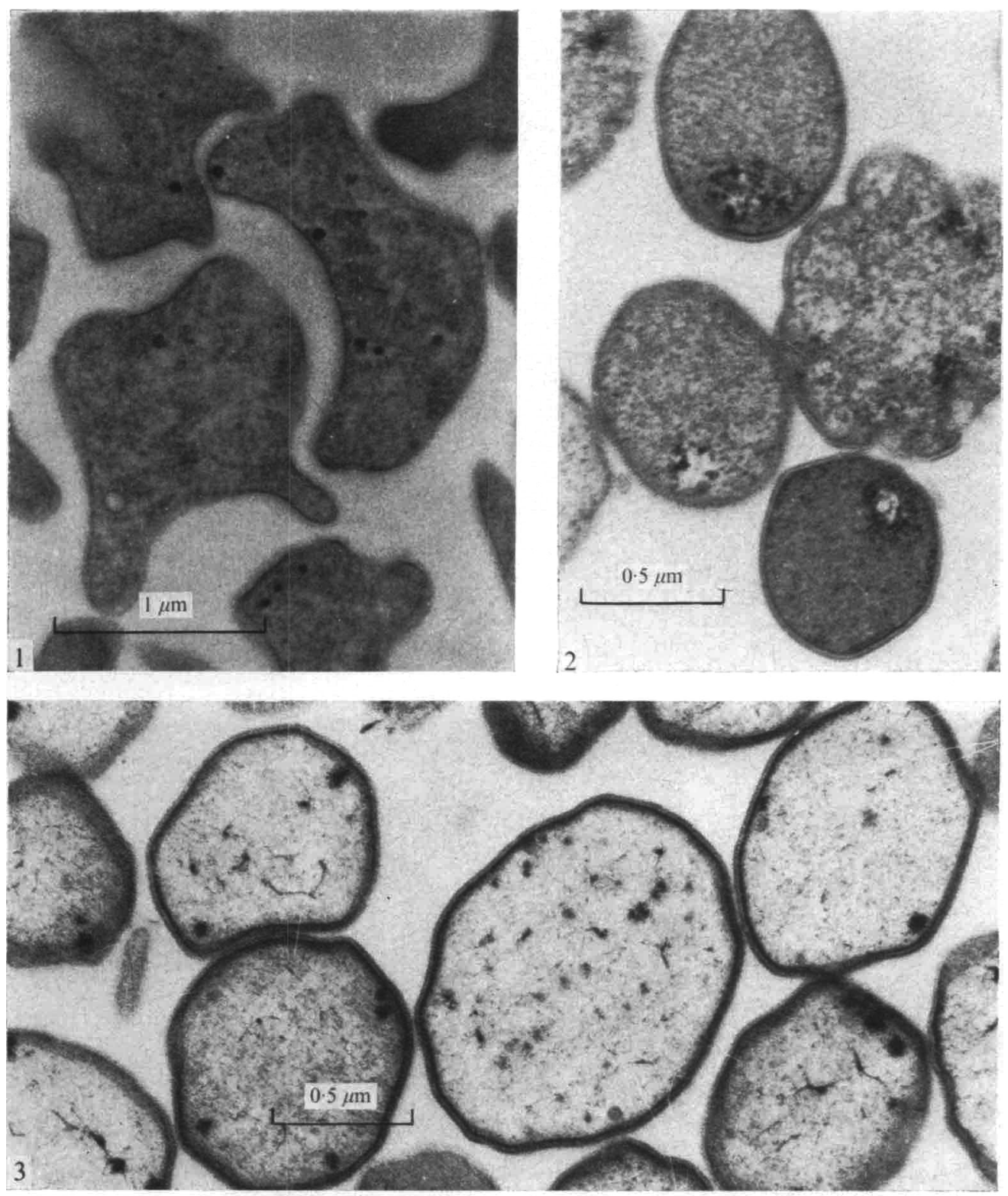

Fig. I. MT3 cells ( $8 \mathrm{~h}$ culture), fixed and embedded after centrifuging at $3000 \mathrm{~g}$, showing bizarre forms due to compression in the pellet. Fixation, glutaraldehyde-osmium tetroxide (GA-Os); staining, uranyl acetate-lead citrate $(\mathrm{U}-\mathrm{Pb})$.

Fig. 2. Cells from low-speed centrifugation (below $1500 \mathrm{~g}$ ); otherwise as Fig. I. Cells dense and rounded, 0.5 to $\mathrm{I} \cdot \mathrm{O} \mu \mathrm{m}$ diameter, bounded by two osmiophilic layers, with small granules (ribosomes?) throughout the cytoplasm and clusters of dense granules in a small less-dense area.

Fig. 3. As Fig. 2, but fixed with osmium only; cells somewhat swollen. Dense filaments and granules represent condensed DNA. 

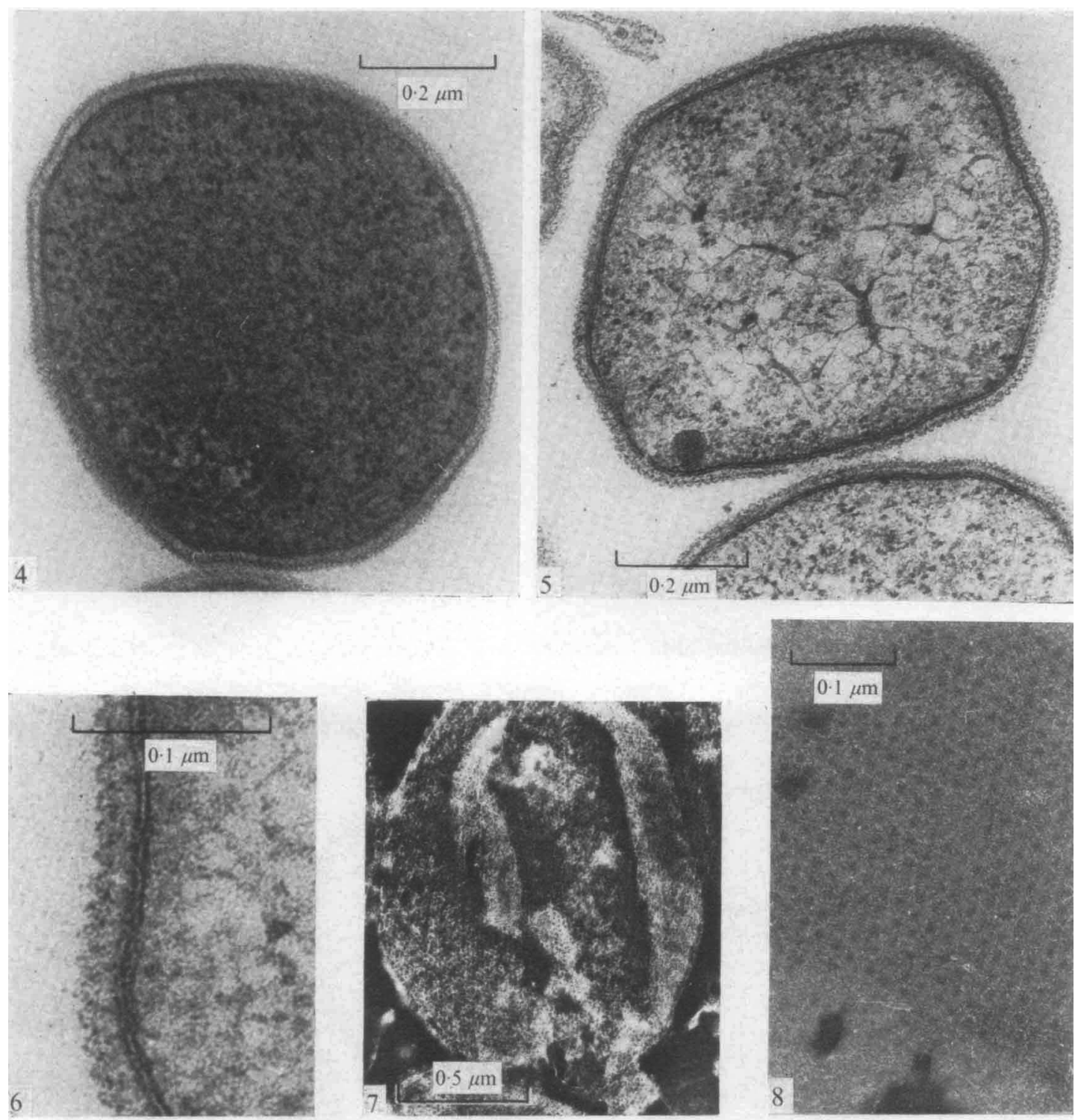

Fig. 4. Cells GA-Os fixed, showing ribosomal and larger granules; the unit membrane is resolved and the extracellular coat seen as an inner clear zone and an outer dense layer.

Fig. 5. Cells Os fixed. Fibres of coagulated DNA evenly distributed throughout the cell volume; unit membrane and extracellular structure resolved.

Fig. 6. Cells GA-Os fixed. The plasma membrane is about $7.5 \mathrm{~nm}$ thick, the extracellular clear layer about $\mathrm{I} 0 \mathrm{~nm}$ and the dense outer layer with arched structure about $8 \mathrm{~nm}$.

Fig. 7. Surface coat 'ghost' negatively stained with phosphotungstic acid (PTA).

Fig. 8. Surface coat 'ghost' - the negative (PTA) stain has filled the globular spaces within the clear layer and the dense dots are in hexagonal array with $20 \mathrm{~nm}$ spacing. 

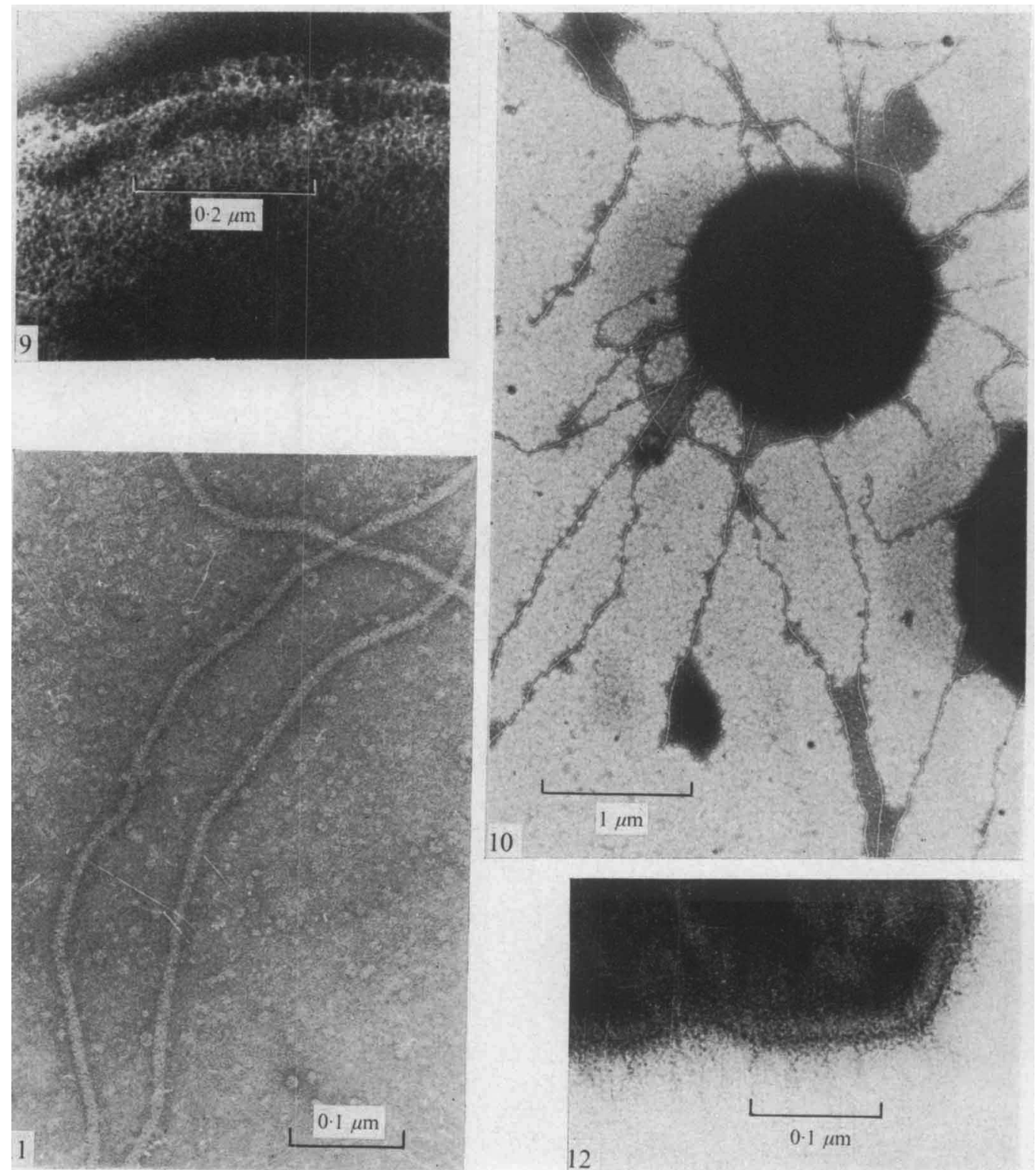

Fig. 9. Specimen as Fig. 7. Each globular space is about $23 \times 15 \mathrm{~nm}$.

Fig. 10. Negatively stained cell showing numerous pili.

Fig. I I. Pili, apparent diameter about $10 \mathrm{~nm}$.

Fig. I2. Thin fibres, up to $50 \mathrm{~nm}$ high, emerging from the coat material. Such fibres are observed occasionally, and are particularly evident in samples fixed in the culture medium at pH 3.6 (GA; centrifuged at $17000 \mathrm{~g}$; Os; U-Pb). 

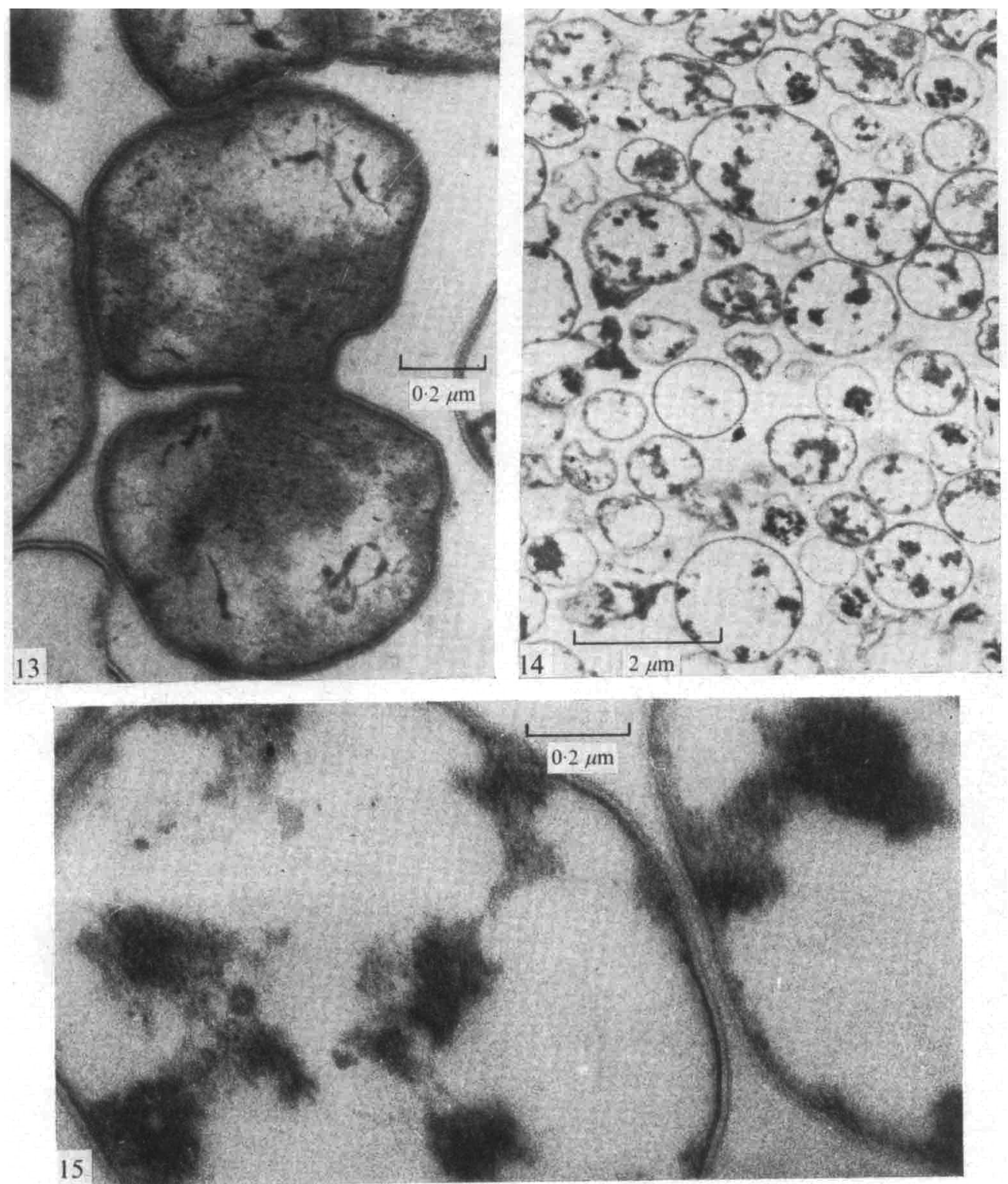

Fig. 13. Replication by binary fission (Os-fixed). Denser cytoplasm is concentrated around the constriction and near the membrane, and two clear nuclear areas with coagulated DNA strands are visible.

Fig. 14. Cell ghosts in an old (92 h) culture (GA-Os).

Fig. I5. As Fig. 14. The cytoplasm is coagulated by the acid culture medium, but the plasma membrane and cell coat are still distinct. 
as such by positive or negative staining, the globular space has had to be considered empty. In tangential sections the clear layer is mainly represented by the empty cavities and the dense layer by coat material. This material did not stain with ruthenium red, suggesting the absence of glycoproteins.

Negative staining revealed more convincingly the substructure of the extracellular coat (Figs. 7 and 8). The 'globular spaces' were filled by the phosphotungstic acid (PTA) and a surface view demonstrates their hexagonal arrangement. Along the rim of the membraneous coat the arch-like structures were particularly well distinguished in negative contrast (Fig. 9). Each space, now filled with PTA, was apparently elliptic (about $15 \times 23 \mathrm{~nm}$ ) with the long axis radially oriented.

The presence of pili with a diameter of about $\mathrm{I} 0 \mathrm{~nm}$ was demonstrated by negative staining (Figs. Io and I I). Some cells possessed as many as ten pili, but many detached and broken pili were also seen and they are apparently very fragile. The exact length was not determined but pili up to $5 \mu \mathrm{m}$ long were seen. These pili were numerous on cells from either stationary or agitated heterotrophic cultures provided only that yeast extract was included in the medium (de Rosa, Gambacorta \& Bu'Lock, 1975).

When organisms were fixed by adding glutaraldehyde to the culture medium at $\mathrm{pH} 3.5$ and observed in sections, their surfaces sometimes appeared to be covered by a large number of extremely thin hairlike fibres (Fig. I2). These apparently did not arise from the plasma membrane, but from the cell coat. Since their inherent contrast in sections is low, it was difficult to determine their real thickness (probably well below $7 \mathrm{~nm}$ ) or their real length. They could be discerned at up to $50 \mathrm{~nm}$ from the cell coat, but since the sections are only about $60 \mathrm{~nm}$ thick they might indeed be much longer. The interpretation of these structures is at present difficult.

Dumb-bell shaped cells are interpreted as dividing cells, supporting the view of binary fission as the mode of replication. After osmium fixation of cells in this state a distinct nucleoid with DNA strands appeared (Fig. 13). As division proceeded, the area elongated and subsequently two nucleoids were formed, separated by cytoplasm considerably denser than in resting cells. Constriction in this area separated the organisms into two daughter cells. The frequency of divisions observed was very low (one per several thousand) even in cultures in the logarithmic growth phase. Septation as in bacteria, or filament formation or budding as described in some species of mycoplasmas, has not been observed.

In ageing cultures the number of dead cells increased constantly, particularly after the logarithmic phase (Fig. I4). They appeared as large (up to Io $\mu \mathrm{m}$ ) empty vesicles, or as collapsed ghosts, in which cell membrane and cell coat could still be recognized (Fig. I5). Inside, a few dense amorphous granules were observed, suspended in a completely transparent phase. The acid culture medium evidently causes the coagulation of the protoplasm when the cells die. Under the optical microscope the cell ghosts are easily distinguished from viable cells.

\section{DISCUSSION}

The bacteriological and biochemical results presented in a preliminary communication (de Rosa et al. 1974) and in the preceding paper (de Rosa et al. 1975) bring out the similarities and differences within a group of acidothermophilic micro-organisms tentatively designated Caldariella; they include the MT strains, Sulfolobus acidocaldarius (Brock, Brock, Belly \& Weiss, 1972), the micro-organism described by Brierley \& Brierley (1973), and Thermoplasma acidophila (Darland, Brock, Samsonoff \& Conti, 1970).

Observations of the MT strains at the ultrastructural level have shown the following 
characteristic features: almost spherical cells, very plastic under centrifugation, bounded by a plasma membrane and covered externally by a non-rigid coat with a macromolecular subunit structure; ribosomes and DNA strands uniformly distributed throughout the cytoplasm, but the DNA condensed into a clear nucleoid area during cell division; replication occurring by binary fission through cell constriction; pili present, and occasionally electron-dense intracellular aggregates; mesosomes and the peptidoglycan layer of typical bacteria absent.

Not all of these features have been reported for each bacterium of this group, but a comparison between the MT strains and the other species is made difficult since not all of them have been studied by the same fixation methods and negative staining has not been applied in all cases. The mode of replication in this group has not been described previously.

Cells of the MT strains are essentially spherical when observed alive in the culture medium (by phase contrast) and also with the electron microscope in sectioned or in negatively stained material. Bizarre forms were described in Sulfolobus (Brock et al. 1972) and in the organism studied by Brierley \& Brierley (1973), but in both cases considerably faster centrifugation ( 8000 to $27000 \mathrm{~g}$ ) was used to harvest the cells. The MT cells show similar multilobed structures when compressed into pellets for processing and embedding into resin; frequently the section of groups of organisms match up like parts of a jigsaw puzzle (de Rosa et al. 1974).

Our observations suggest that the regularly-structured extracellular coat is identical in MT cells and Sulfolobus (cf. Brock et al. 1972). Brierley \& Brierley (1973) describe only an 'amorphous extracellular layer' around their organism and in their micrograph a distinct extracellular layer is visible. The absence of a coat in sectioned and in freeze-etched preparations of Thermoplasma was shown by Darland et al. (1970).

Indirect evidence for the absence of a peptidoglycan-based wall comes from the insensitivity of the MT cells to vancomycin (de Rosa et al. 1975), which is paralleled in Sulfolobus (Brock et al. 1972). The insensitivity of Thermoplasma to vancomycin was used to support the view that this organism should be classed with the mycoplasmas (Darland et al. 1970), and only the presence of the extracellular coat would seem to contra-indicate such a classification for Sulfolobus and the MT isolates. In fact, although the absence of an extracellular coat in mycoplasmas is usually considered a criterion for their characterization it now appears that in several 'typical' mycoplasmas some sort of extracellular coat may be present (Maniloff \& Morowitz, 1972). Some published electrographs of typical mycoplasmas such as Mycoplasma gallisepticum (Morowitz \& Maniloff, 1966) and M. arthritidis H39 (Maniloff, 1969) reveal a coat outside the cell membrane.

In the electrographs of the glutaraldehyde-osmium fixed Sulfolobus, dense intracellular aggregates of granular material like those found in MT cells are present although these were not discussed (Brock et al. 1972). A strict comparison between the granules which were observed by Brierley \& Brierley (1973) in their organism is not possible, but it may be that they represent equivalent structures. In MT cells, their presence is not related to any one stage of development, as they appear occasionally in both young and old cultures, grown with or without Casamino acids, and they are preserved after both methods of fixation.

By fixing the MT cells with osmium tetroxide only, it was possible to visualize the DNA strands. They were uniformly distributed during interphase and not condensed into a nucleoid as in typical bacteria. It is noteworthy that the internal structure (and particularly the pattern and distribution of DNA) of MT cells was surprisingly similar to Mycoplasma pneumoniae (Zucker-Franklin, Davidson \& Thomas, 1966). Only during cell division does any distinct nuclear area appear.

No replication figures have been described for the other organisms of this group; although 
not demonstrated by electron microscopy, it was presumed that Sulfolobus might reproduce by septation of the lobes and Thermoplasma by budding (Brock et al. 1972; Darland et al. I970).

The frequency of dividing cells was found to be extremely low, even when sampling during the logarithmic phase of growth, and it is reasonable to conclude that the actual division time is rather short, in the range of minutes.

In Sulfolobus Weiss (1973) revealed pili by negative staining. They were particularly numerous in isolates from flowing springs, but after a few transfers in basal medium the bacteria lacked pili and were unable to attach to sulphur particles. Our observations did not extend to the mode of attachment to sulphur but we observed that the presence of yeast extract in the medium was sufficient to ensure the presence of pili in agitated cultures. The pili appear to be particularly fragile and their mode of attachment is obscure.

The absence in MT cells of a typical bacterial (peptidoglycan) wall, of a nucleoid during the resting stage, and of mesosomes makes it difficult to classify this organism with typical bacteria, at least on morphological grounds. A similarly primitive fine structure is present in bacterial L-forms and in mycoplasmas only (Smith, 1971). Typical L-forms, for example, of Bacillus subtilis (Gilpin, Young \& Chatterjee, 1973), lack a cell wall and replicate by fission, but vary considerably in size and display a nuclear area. The MT organism has many features in common with the mycoplasmas, except for its extracellular coat; however, improved visualization of the full range of fine-structure features in 'typical' mycoplasmas may eventually allow us to classify more definitively not only the MT isolates but also Sulfolobus, Thermoplasma, and other apparently related organisms.

\section{REFERENCES}

Brierley, C. L. \& Brierley, J. A. (1973). A chemoautotrophic and thermophilic microorganism isolated from an acid hot spring. Canadian Journal of Microbiology 19, 183-188.

Brock, T. D., Brock, K. M., Belly, R. T. \& Weiss, R. L. (1972). Sulfolobus: a new genus of sulfur oxidizing bacteria living at low pH and high temperature. Archiv für Mikrobiologie 84, 54-68.

Darland, G., Brock, T. D., Samsonoff, W. \& Conti, S. F. (1970). A thermophilic acidophilic Mycoplasma isolated from a coal refuse pile. Science, New York 170, 1416-1418.

Gilpin, R. W., Young, F. E. \& ChatterJee, A. N. (I973). Characterization of a stable L-form of Bacillus subtilis 168 . Journal of Bacteriology I13, 486-499.

MANILoff, J. (1969). Electron microscopy of small cells: Mycoplasma hominis. Journal of Bacteriology 1oo, I 402-1408.

Maniloff, J. \& Morowitz, J. H. (I972). Cell biology of Mycoplasmas. Bacteriological Reviews 36, $263-284$.

Morowitz, H. J. \& MANILOFf, J. (I966). Analysis of the life cycle of Mycoplasma gallisepticum. Journal of Bacteriology 91, 1638-I 644 .

de Rosa, M., Gambacorta, A. \& Bu'Lock, J. D. (1975). Extremely thermophilic acidophilic bacteria convergent with Sulfolobus acidocaldarius. Journal of General Microbiology 86, I 56-I 64.

de Rosa, M., Gambacorta, A., Millonig, G. \& Bu’Lock, J. D. (I974). Convergent characters of extremely thermophilic acidophilic bacteria. Experientia (in the Press).

Smith, P. F. (197I). The Biology of Mycoplasmas. New York: Academic Press.

SPURR, A. R. (1969). A low-viscosity epoxy resin embedding medium for electron microscopy. Journal of Ultrastructure Research 26, $3 \mathrm{I}-43$.

Werss, R. L. (1973). Attachments of bacteria to sulphur in extreme environments. Journal of General Microbiology 77, 501-507.

Zucker-Franklin, D., Davidson, M. \& Thomas, L. ( I966). The interaction of Mycoplasmas with mammalian cells. I. HeLa cells, neutrophils, and eosinophils. Journal of Experimental Medicine 124, 52 I-532. 